\title{
Наднациональные гарантии свободы средств массовой информации: опыт постсоветских интеграций
}

\author{
Тульнев М.А. \\ Белгородский государственный национальный исследовательский университет, \\ Россия, 308015, г. Белгород, ул. Победы, 85 \\ E-mail: 738330@bsu.edu.ru
}

\begin{abstract}
Аннотация. Свобода средств массовой информации, провозглашенная не только на государственном конституционном уровне, но и международном, закономерно опосредует и наднациональные гарантии заявленной свободы, тем более, что важность ее реализации в связи информационными войнами и фейковыми новостями обоснованно является межгосударственной. В данной связи автором осуществлен анализ международных правовых актов постсоветского пространства, участником которых является Российская Федерация, с целью выявления в них легализации гарантий свободы средств массовой информации. Установлено, что в рамках постсоветского пространства гарантирование свободы средств массовой информации сложилось в Союзном государстве России и Беларуси, Содружестве независимых государств, включая модельное законодательство; на основе двусторонних договорённостей в сфере информации или обеспечения статуса журналистов.
\end{abstract}

Ключевые слова: гарантии, договор, конвенция, свобода средств массовой информации, модельный закон, содействие, ограничение, журналист.

Для цитирования: Тульнев М.А. 2020. Наднациональные гарантии свободы средств массовой информации: опыт постсоветских интеграций. NOMOTHETIKA: Философия. Социология. Право. 45 (2): 336-344. DOI 10.18413/2712-746X-2020-44-2-336-344

\section{Supranational guarantees of media freedom information: experience of post-soviet integrations}

\author{
Michael A. Tulnev \\ Belgorod National Research University, \\ 85 Pobeda St, Belgorod, 308015, Russia \\ E-mail: 738330@bsu.edu.ru
}

\begin{abstract}
Freedom of the media, proclaimed not only at the state constitutional level, but also at the international level, naturally mediates supranational guarantees of the declared freedom. Moreover, the importance of its implementation in connection with information wars and fake news is justifiably interstate. In this regard, the author analyzes international legal acts of the post-Soviet space, to which the Russian Federation is a party, in order to identify the legalization of guarantees of freedom of the mass media. It is established that within the post-Soviet space, the guarantee of freedom of the mass media has developed in the Union state of Russia and Belarus, the Commonwealth of independent States, including model legislation; on the basis of bilateral agreements in the field of information or ensuring the status of journalists. It is concluded that, in addition to bilateral initiatives and model laws, the guarantee formats are fragmented and require a comprehensive «package» approach of integrations to the special legalization of mass media freedom, taking into account the variability of its sources and guarantees.
\end{abstract}


Keywords: contract, Convention, freedom of the media, model law, assistance, restriction, journalist.

For citation: Michael A.T. 2020. Supranational guarantees of media freedom information: experience of post-soviet integrations. NOMOTHETIKA: Philosophy. Sociology. Law series. 45 (2): 336-344 (in Russian). DOI 10.18413/2712-746X-2020-44-2-336-344

\section{Введение}

В процессе эволюции человеческое общество все в большей степени осознавало ценность, значимость и действенность информации, которая определялась не только как инструмент познания окружающего мира и основа для коммуникативных связей, мощное орудие консолидации и созидания, но также как невероятно действенное всеразрушающее оружие, по своей силе порой превосходящее известные виды вооружений [Сулейманова, Назарова, 2017, с. 4].

Одним их правовых инструментов противодействия современным информационным войнам является гарантирование свободы массовой информации [Погребинская, 2009; Фролова, 2012], исключение ее цензуры [Куликова, 2011; Марцоха, 2007; Пальцева, 2008; Трофимов, 2010], зависимости и идеологизации [Лукашук, 2011, Малько, 2001].

Свобода средств массовой информации, провозглашенная не только на государственном конституционном уровне, но и международном, закономерно опосредует и наднациональные гарантии заявленной свободы, тем более, что важность ее реализации обоснованно является межгосударственной.

Уточним, что ключевые международные документы универсального характера в базовом варианте все-таки исходят из свободы выражения своего мнения различными способами, в том числе посредством печати. К примеру, ч. 2 ст. 2 Международного пакта о гражданских и политических правах установлено, что каждый человек имеет право на свободное выражение своего мнения; это право включает свободу искать, получать и распространять всякого рода информацию и идеи, независимо от государственных границ, устно, письменно или посредством печати, или художественных форм выражения, или иными способами по своему выбору. Тожественен подход и Конвенции о защите прав человека и основных свобод 1950 г. (ст. 10) ${ }^{1}$.

\section{Гарантии свободы средств массовой информации в рамках СНГ}

Помимо участия Российской Федерации в международных универсальных и региональных интеграциях, с геополитической, экономической и культурной сторон важно ее состояние в локальном объединении - Содружестве независимых государств ${ }^{2}$ (далее СНГ). Отметим, что в настоящее время СНГ является формой кооперации равноправных независимых государств, характеризующейся особенностями взаимодействия практически во всех сферах, гибкостью механизмов и форматов коллективного сотрудничества. Многообразие контактных сфер регламентировано имманентными многосторонними правовыми актами, среди которых, полагаем, наличествуют и гарантии свободы средств массовой информации.

${ }^{1}$ Конвенция о защите прав человека и основных свобод (ETS № 5) (Заключена в г. Риме 04.11.1950) // СЗ РФ. 1998. № 20. Ст. 2143.

${ }^{2}$ Решение Совета глав государств СНГ «О принятии Устава СНГ» (Вместе с «Уставом Содружества Независимых Государств») (принято в г. Минске 22.01.1993) // Бюллетень международных договоров. 1994. № 1; Постановление ВС РФ от 15.04.1993 № 4799-1 «О ратификации Устава Содружества Независимых Государств» // Ведомости СНД и ВС РФ. 1993. № 17. Ст. 608. 
Конвенция о правах и основных свободах человека, принятая в рамках СНГ, последовала примеру универсального и регионального стандартов прав личности, легализовав в ст. 11 свободу выражения своего мнения любым законным способом без вмешательства со стороны государственных властей и независимо от государственных границ, при этом обозначив известные основания для ограничения свободы ${ }^{1}$.

Поясним, что специальный документ, посвященный регламентации отношений в связи с реализацией свободы средств массовой информации и ее гарантированием, в данном интегративном сообществе отсутствует.

Вместе с тем в СНГ все-таки прилагаются точечные усилия в направлении гарантирования свободы массовой информации, что выражено, к примеру, в учреждении такой институции, как Межгосударственный совет по сотрудничеству в области периодической печати, книгоиздания, книгораспространения и полиграфии (далее - Межгосударственный совет). Он предназначен для создания условий широкого и свободного обмена и распространения печатной продукции, производимой на территориях Сторон.

Решения этого Совета носят рекомендательный характер, а расходы по проведению заседаний несет государство - участник Соглашения, на территории которого проводится заседание Совета. Расходы же по командированию членов Совета несет направляющее государство ${ }^{2}$.

Следует отметить, что деятельность Межгосударственного совета осуществляется и в настоящее время на систематической основе. Так, в 2019 г. на его заседании была утверждена новая редакция Положения о Международном конкурсе «Искусство книги» государств - участников СНГ. Полагаем, подобного рода конкурсные мероприятия важны и обладают гарантирующим потенциалом в аспекте популяризации определенной разновидности информации.

В целом деятельность указанного Межгосударственного совета в полной мере соотносима с принятым в 2004 г. Соглашением о сотрудничестве в области книгоиздания, книгораспространения и полиграфии ${ }^{3}$.

Представляется, наличие приведенных документов, безусловно, оказывает плодотворное влияние на гарантирование распространения книжной, полиграфической продукции. Вместе с тем в условиях информационного общества, признаваемого государствами на правовом уровне, с учетом опыта, к примеру, европейской интеграции ${ }^{4}$, рекомендательны разработка и принятие правовых актов, легализующих свободу средств массовой информации с учетом их современной вариативности, а также с надлежащими гарантиями

\footnotetext{
${ }^{1}$ Конвенция Содружества Независимых Государств о правах и основных свободах человека (заключена в г. Минске 26.05.1995) // СЗ РФ. 1999. № 13. Ст. 1489.

${ }^{2}$ Соглашение о создании Межгосударственного совета по сотрудничеству в области периодической печати, книгоиздания, книгораспространения и полиграфии (Вместе с «Положением...») (заключено в г. Минске 04.06.1999) // Бюллетень международных договоров. 2001. № 4. C. 19-23.

${ }^{3}$ Соглашение о сотрудничестве в области книгоиздания, книгораспространения и полиграфии (Заключено в г. Чолпон-Ате 16.04.2004) // Бюллетень международных договоров. 2008. № 5. С. $15-18$.

${ }^{4}$ Cм., например: рекомендации Комитета Министров Совета Европы № CM/Rec (2016)5 «О свободе в Интернете» (принята 13.04.2016 на 1253-ом заседании заместителей министров) // Прецеденты Европейского Суда по правам человека: Электронное периодическое издание / учредитель ООО «Развитие правовых систем». 2016. № 6 (30). С. 114-120; № CM/Rec (2018)1 «О плюрализме средств массовой информации и транспарентности собственности на средства массовой информации» (принята 07.03.2018 на 1309-ом заседании представителей министров) // Бюллетень Европейского суда по правам человека. Российское издание. 2018. № 10 и др.
} 
на декларативном уровне. В последующем такой опыт может быть воспроизведен на конвенционном уровне. Возвращаясь к базовому документу СНГ о правах человека, в качестве пробела видится отсутствие в нем формализованного запрета на цензуру. Таким образом, в условиях необходимости обеспечения международной и национальной безопасности, в том числе от распространенных информационных, фейковых новостей, целесообразна «пакетная» работа уполномоченных структур СНГ по легализации надлежащих гарантий свободы массовой информации, тем более, что подобного рода опыт имеется в рамках договорных межгосударственных отношений.

\section{Договорные гарантии свободы средств массовой информации}

В этой связи далее авторское внимание уделено специальным международным договорам Российской Федерации, являющимся частью ее правовой системы. Их предметом выступает свобода средств массовой информации и ее гарантии.

Как правило, искомые гарантии выражены в межправительственных двусторонних соглашениях в области информации или массовых коммуникаций. В содержании таких соглашений гарантирующая роль принадлежит следующим формулировкам:

«Каждая из Сторон будет способствовать широкому и свободному обмену информацией между информационными службами (агентствами) и редакциями средств массовой информации, не будет препятствовать распространению на территории ее государства продукции средств массовой информации, которые зарегистрированы и действуют на законных основаниях в государстве другой Стороны, при условии, что распространение сведений и материалов, образующих такую продукцию, не противоречат требованиям ее национального законодательства.

Каждая из Сторон не будет препятствовать распространению сообщений и информации дипломатических и иных официальных представительств государства другой Стороны» (ст. 2) ${ }^{1}$.

Аналогичен смысл соглашения о сотрудничестве в области информации между Российской Федерацией и Киргизией ${ }^{2}$. Однако позднее приведенному специальному двустороннему соглашению на смену пришла Декларация о вечной дружбе, союзничестве и партнерстве между Российской Федерацией и Киргизской Республикой. Она, будучи содержательно универсальным документом, регулирующим широкий перечень вопросов, уделила внимание и свободе средств массовой информации. В частности, каждая из Сторон будет обеспечивать своим гражданам свободный доступ к средствам массовой информации другой Стороны, создавать благоприятные условия для объективного освещения процессов, происходящих в обоих государствах. С этой целью Стороны будут всемерно содействовать расширению информационного обмена между двумя странами и созданию максимально благоприятных условий для деятельности журналистов Сторон на своей территории ${ }^{3}$.

Заключаемые в современный период двусторонние соглашения уже посвящены сотрудничеству в области массовых коммуникаций. Так, помимо уже приведенных ранее

${ }^{1}$ Соглашение между Правительством Российской Федерации и Правительством Республики Таджикистан о сотрудничестве в области информации (заключено в г. Душанбе 16.10.2004) // Бюллетень международных договоров. 2005. № 6. С. 72-74.

${ }^{2}$ Соглашение о сотрудничестве в области информации (заключено в г. Бишкеке 09.10.1992 г.) // Бюллетень международных договоров. 1993. № 10. С. 30-32.

${ }^{3}$ Декларация о вечной дружбе, союзничестве и партнерстве между Российской Федерацией и Киргизской Республикой (принята в г. Москве 27.07.2000) // Дипломатический вестник. 2000. № 8. С. 65-68. 
положений, к примеру, в соглашении между правительствами Российской Федерации и Республики Конго установлено, что Стороны на основе принципов равноправия и взаимной выгоды развивают долгосрочное сотрудничество в области массовых коммуникаций, способствуют созданию благоприятных условий для широкого и свободного распространения информации в соответствии со своим национальным законодательством и в целях дальнейшего углубления знаний о жизни народов своих государств (ст. 1) 1 .

Кроме того, договорно-гарантирующими расцениваем положения, в соответствии с которыми Стороны

- развивают сотрудничество на основе взаимных консультаций, обмена опытом и информацией по следующим направлениям в сфере массовых коммуникаций: обмен опытом в области современных способов и технологий распространения информации, производства аудиовизуальной продукции и хранения архивных данных; сотрудничество в области медиаиндустрии (ст. 2);

- поддерживают и поощряют взаимовыгодное сотрудничество между редакциями средств массовой информации государств, а также между соответствующими ведомствами и организациями, работающими в области средств массовой информации (ст. 4);

- содействуют равноправному и взаимовыгодному сотрудничеству между профессиональными организациями журналистов государств Сторон с целью изучения проблем, представляющих профессиональный интерес, а также проведению встреч, семинаров и конференций в области средств массовой информации (ст. 5);

- в соответствии с национальным законодательством государств оказывают помощь в работе находящимся на территории государства аккредитованным представителям средств массовых коммуникаций, а также агентствам, журналистам и съемочным группам (ст. 6).

Отметим, что ранее вопросы о статусе корреспондентов средств массовой информации не были интегрированы в обобщенные соглашения об информации или массовых коммуникациях и составляли отдельный самостоятельный предмет. Здесь уместен пример Соглашения между Правительством Российской Федерации и Правительством Азербайджанской Республики о статусе корреспондентов средств массовой информации. Гарантирующими свободу массовой информации нормами, в том числе, выступали следующие установления:

- Стороны через уполномоченные органы в рамках национального законодательства всемерно содействуют получению и распространению иностранными корреспондентами объективной информации о политической, социально-экономической и культурной жизни государства аккредитации, соблюдению общепризнанных норм журналистской этики (ст. 3);

- иностранным корреспондентам на основе взаимности с учетом требований национального законодательства предоставляется право свободного передвижения на территории Российской Федерации и Азербайджанской Республики, за исключением районов и объектов, для посещения которых установлен специальный порядок (ст. 6).

- Стороны в соответствии с общепризнанными нормами международного права через уполномоченные органы обеспечивают соблюдение прав иностранных корреспондентов на свободную передачу средствам массовой информации своих материалов, радио, видео- и телеинформации без какой-либо цензуры (ст. 7)².

${ }^{1}$ Соглашение между Правительством Российской Федерации и Правительством Республики Конго о сотрудничестве в области массовых коммуникаций (Заключено в г. Москве 23.05.2019). На 25.04.2020 документ не вступил в силу // http://www.mid.ru/

${ }^{2}$ Соглашение между Правительством Российской Федерации и Правительством Азербайджанской Республики о статусе корреспондентов средств массовой информации Российской Федерации в Азербайджанской Республике и корреспондентов средств массовой информации Азер- 
Аналогичное межправительственное соглашение было заключено Россией и Арменией ${ }^{1}$.

Интересно, что в рамках двусторонних союзных форм сотрудничества также обнаружены искомые, но все же точечные гарантии (как и в СНГ). Так, Российская Федерация и Республика Беларусь, создав Союзное государство ${ }^{2}$, утвердили Устав Телерадиовещательной организации Союзного государства. Ее срок деятельности не ограничен ${ }^{3}$.

Организация осуществляет деятельность в области телерадиовещания и электронных средств массовой информации, взаимодействия и сотрудничества с телерадиовещательными организациями на территории Российской Федерации, Республики Беларусь и за рубежом в целях обеспечения основной деятельности и участия в формировании рынка аудиовизуальной продукции, трансляции телерадиопрограмм, участия в международном теле- и радиообмене, создания условий для работы на территории государств-участников Союзного государства и за рубежом (п. 1.3.).

Координация работы Организации и ее взаимодействие с национальными органами государств-участников Союзного государства осуществляется Постоянным Комитетом Союзного государства (1.5.).

Несмотря на наличие указанной институциональной гарантии, полагаем, для такого серьезного союзного объединения также рекомендательны разработка и принятие «пакетных» специальных гарантирующих положений о свободе средств массовой информации.

\section{Роль модельных законов в гарантии свободы средств массовой информации}

В качестве современного перспективного направления гармонизации и унификации национальных правовых систем следует упомянуть международные модельные законы [Касымжанова, 2012], под которыми понимают нормы, управомочивающие или обязывающие государства или других субъектов разработать и принять правовые акты или правовые нормы (международные или внутригосударственные) определенного содержания [Безбородов, 2008].

В рамках интеграции СНГ указанная форма унификации популярна и применяется в различных сферах, в том числе и рассматриваемой нами сфере средств массовой информации. Отметим, что принимаемые в СНГ модельные законы не всегда воспринимаются национальной российской системой, но в подавляющем числе случаев находят адаптацию. Иногда модельные законы интеграции формируются на основе национальных правовых актов. Здесь ярким примером является Модельный закон об информации, информатизации и обеспечении информационной безопасности ${ }^{4}$, принятый 8 лет спустя

байджанской Республики в Российской Федерации (Заключено в г. Баку 09.01.2001) // Бюллетень международных договоров. 2004. № 9. С. 41-44.

${ }^{1}$ Бюллетень международных договоров. 2005. № 10. С. 17-19.

2 Договор между Российской Федерацией и Республикой Беларусь о создании Союзного государства (подписан в г. Москве 08.12.1999) // СЗ РФ. 2000. № 7. Ст. 786.

${ }^{3}$ Постановление № 6 от 10.03.2004 Совета Министров Союзного государства «Об Уставе, составе коллегии и предельной штатной численности работников Телерадиовещательной организации Союзного государства» // Документы, принятые и одобренные на заседании Совета Министров Союзного государства (Протокол заседания Совета Министров Союзного государства от 10 февраля 2004 г. № 1). С. 271-290.

${ }^{4}$ Модельный закон об информации, информатизации и обеспечении информационной безопасности (принят в г. Санкт-Петербурге 28.11.2014. Постановлением 41-15 на 41-ом пленарном заседании Межпарламентской Ассамблеи государств-участников СНГ) // Документ опубликован не был; http://www.consultant.ru/ (дата обращения 10.04.2020). 
после российского федерального закона № 149-Ф3 «Об информации, информационных технологиях и о защите информации» ${ }^{1}$.

Для национальной правовой системы опережающий характер имел модельный закон о критически важных объектах информационно-коммуникационной инфраструктуры $^{2}$. Лишь через 3 года в России был принят федеральный закон № 187-Ф3 «О безопасности критической информационной инфраструктуры Российской Федерации» ${ }^{3}$. Указанные национальный и модельный документы структурно и содержательно имеют сходство. Однако следует акцентировать внимание на положительном моменте федерального закона № 187-Ф3 «О безопасности критической информационной инфраструктуры Российской Федерации» по сравнению с модельным - включение в ст. 4 принципов обеспечения безопасности критической информационной инфраструктуры. В числе принципов названы:

- законность;

- непрерывность и комплексность обеспечения безопасности критической информационной инфраструктуры, достигаемые в том числе за счет взаимодействия уполномоченных федеральных органов исполнительной власти и субъектов критической информационной инфраструктуры;

- приоритет предотвращения компьютерных атак.

Вместе с тем национальный правовой акт проигнорировал порядок исключения объектов информационно-коммуникационной инфраструктуры из числа критически важных. Полагаем, такой порядок рекомендуется к заимствованию из Модельного закона о критически важных объектах информационно-коммуникационной инфраструктуры (Глава 8) и включению в федеральный закон № 187-ФЗ в качестве дополняющей ч. 13 ст. 7.

В 2012 г. был принят модельный информационный кодекс для государствучастников СНГ ${ }^{4}$. Однако соответствующий опыт не был воспринят российской правовой системой. Не вдаваясь в дискуссию о возможной кодификации рассматриваемой сферы, уточним, что современное действующее законодательство считаем достаточным, хотя и не отрицаем идеи его систематизации в едином документе, тем более, что в настоящее время перечень источников информации характеризуется вариативностью, и их статутизация в одном документе способствовала бы упрощению правоприменительной практики.

\section{Заключение}

Подводя итоги исследования, отметим, что в рамках постсоветского пространства гарантирование свободы средств массовой информации сложилось в Союзном государстве России и Беларуси, Содружестве независимых государств, включая модельное законодательство, на основе двусторонних договорённостей в сфере информации или обеспечения статуса журналистов.

${ }^{1}$ Федеральный закон от 27.07.2006 № 149-Ф3 «Об информации, информационных технологиях и о защите информации» (ред. от 03.04.2020) // С3 РФ. 2006. № 31 (1 ч.). Ст. 3448; Официальный интернет-портал правовой информации http://www.pravo.gov.ru, 03.04.2020.

${ }_{2}^{2}$ Модельный закон о критически важных объектах информационно-коммуникационной инфраструктуры (принят в г. Санкт-Петербурге 28.11.2014 Постановлением 41-14 на 41-ом пленарном заседании Межпарламентской Ассамблеи государств-участников СНГ) // Документ опубликован не был; http://www.consultant.ru/ (дата обращения 10.04.2020).

${ }^{3}$ Федеральный закон от 26.07.2017 № 187-Ф3 «О безопасности критической информационной инфраструктуры Российской Федерации» // СЗ РФ. 2017. № 31 (Часть I). Ст. 4736.

${ }^{4}$ Модельный информационный кодекс для государств-участников СНГ (Принят в г. СанктПетербурге 23.11.2012 Постановлением 38-6 на 38-ом пленарном заседании Межпарламентской Ассамблеи государств-участников СНГ) // Документ опубликован не был; http://www.consultant.ru/ (дата обращения 10.04.2020). 
Автором установлено, что, кроме двусторонних инициатив и модельного законодательствования, иные форматы гарантирования носят фрагментарный характер, нуждаются в комплексном «пакетном» подходе интеграций к специальной легализации свободы массовой информации с учетом вариативности ее источников и гарантирования.

\section{Список литературы}

1. Безбородов Ю.С. 2008. Международные модельные нормы. М., Волтерс Клувер, 135 с.

2. Касымжанова Д.С. 2012. Влияние модельных законов на национальное законодательство. Вестник Института законодательства Республики Казахстан, 3(27): 164-166.

3. Куликова С.А. 2011. Конституционный запрет цензуры: понятие, признаки и гарантии. Информационное право, 2: 12-16.

4. Лукашук И.И. 2001. Средства массовой информации, государство, право. М., Стольный град, $322 \mathrm{c.}$

5. Малько А.В. 2005. Стимулы и ограничения в праве. М., 250 с.

6. Марцоха И.Е. 2007. Институт цензуры в информационной правовой политике России: Дис. ... канд. юрид. наук. Ростов-на-Дону, 25 с.

7. Пальцева Е.С. 2008. Границы свободы слова журналиста в контексте статьи 23 Конституции РФ. Законодательство и экономика, 7: 52-56.

8. Погребинская Л.А. 2009. Реализация конституционной свободы массовой информации: российское законодательство и практика его применения: Автореф. дис. ... канд. юрид. наук. Тюмень, 21 с.

9. Сулейманова Ш.С., Назарова Е.А. 2017. Информационные войны: история и современность. М., Международный издательский центр «Этносоциум», 124 с.

10. Трофимов М.С. 2010. Конституционный запрет цензуры и свобода массовой информации. Информационное право, 1: 25-28.

11. Фролова И.Г. 2012. Конституционно-правовые гарантии свободы массовой информации в Российской Федерации: Автореф. дис. ... канд. юрид. наук. Саратов, 24 с.

\section{References}

1. Bezborodov YU.S. 2008. Mezhdunarodnye model'nye normy [International model norms]. M., Volters Kluver, 135 p.

2. Kasymzhanova D.S. 2012. Vliyanie model'nyh zakonov na nacional'noe zakonodatel'stvo [Influence of model laws on national legislation]. Vestnik Instituta zakonodatel'stva Respubliki Kazahstan, 3(27): 164-166.

3. Kulikova S.A. 2011. Konstitucionnyj zapret cenzury: ponyatie, priznaki i garantii [Constitutional prohibition of censorship: concept, features and guarantees]. Informacionnoe parvo, 2: $12-16$.

4. Lukashuk I.I. 2001. Sredstva massovoj informacii, gosudarstvo, parvo [Mass media, state, law]. M., Stol'nyj grad, $322 \mathrm{p}$.

5. Mal'ko A.V. 2005. Stimuly i ogranicheniya v prave [Incentives and restrictions in law]. M., $250 \mathrm{p}$.

6. Marcoha I.E. 2007. Institut cenzury v informacionnoj pravovoj politike Rossii [Institute of censorship in the information legal policy of Russia]: Dis. ... kand. yurid. nauk. Rostov-na-Donu, $25 \mathrm{c}$.

7. Pal'ceva E.S. 2008. Granicy svobody slova zhurnalista v kontekste stat'i 23 Konstitucii RF [The limits of a journalist's freedom of speech in the context of article 23 of the Constitution of the Russian Federation]. Zakonodatel'stvo i ekonomika, 7: 52-56.

8. Pogrebinskaya L.A. 2009. Realizaciya konstitucionnoj svobody massovoj informacii: rossijskoe zakonodatel'stvo i praktika ego primeneniya [The implementation of the constitutional freedom of the media: Russian legislation and practice of its application:]: Avtoref. dis. ... kand. yurid. nauk. Tyumen', $21 \mathrm{p}$. 
9. Sulejmanova SH.S., Nazarova E.A. 2017. Informacionnye vojny: istoriya i sovremennost' [Information wars: history and modernity]. M., Mezhdunarodnyj izdatel'skij centr «Etnosocium», 124 p.

10. Trofimov M.S. 2010. Konstitucionnyj zapret cenzury i svoboda massovoj informacii [Constitutional prohibition of censorship and freedom of the media]. Informacionnoe parvo, 1: 25-28.

11. Frolova I.G. 2012. Konstitucionno-pravovye garantii svobody massovoj informacii v Rossijskoj Federacii [Constitutional and legal guarantees of mass media freedom in the Russian Federation]: Avtoref. dis. ... kand. yurid. nauk. Saratov, 24 p.

\section{ИНФОРМАЦИЯ ОБ АВТОРЕ}

Тульнев Михаил Анатольевич, аспирант кафедры конституционного и международного права юридического института Белгородского государственного национального исследовательского университета, Белгород, Россия

\section{INFORMATION ABOUT THE ATHOR}

Michael A. Tulnev, postgraduate student of the Department of constitutional and international law of the law Institute of the Belgorod state national research University, Belgorod, Russia 